\title{
Chronic Hypersensitivity For Inflammatory Nociceptor Sensitization Mediated by the $\epsilon$ Isozyme of Protein Kinase C
}

\author{
K. O. Aley, ${ }^{1}$ Robert O. Messing, ${ }^{2}$ Daria Mochly-Rosen, ${ }^{3}$ and Jon D. Levine ${ }^{1}$ \\ ${ }^{1}$ National Institutes of Health Pain Center, University of California, San Francisco, San Francisco, California 94143-0440, \\ 2Ernest Gallo Clinic and Research Center, University of California, Emeryville, California 94608, and 3Molecular \\ Pharmacology, Stanford University, Stanford, California 94305
}

\begin{abstract}
We have identified a mechanism, mediated by the $\epsilon$ isozyme of protein kinase $\mathrm{C}(\mathrm{PKC} \epsilon)$ in peripheral neurons, which may have a role in chronic inflammatory pain. Acute inflammation, produced by carrageenan injection in the rat hindpaw, produced mechanical hyperalgesia that resolved by $72 \mathrm{hr}$. However, for up to 3 weeks after carrageenan, injection of the inflammatory mediators prostaglandin $E_{2}$ or 5-hydroxytryptamine or of an adenosine $\mathrm{A}_{2}$ agonist into the same site induced a markedly prolonged hyperalgesia ( $>24 \mathrm{hr}$ compared with $5 \mathrm{hr}$ or less in control rats not pretreated with carrageenan). A nonselective
\end{abstract}

In studying mechanisms underlying pain, researchers have been successful in elucidating bases of acute inflammatory pain (for review, see Cesare and McNaughton, 1997; Levine and Reichling, 1999). Although chronic inflammatory pain syndromes (e.g., arthritis, gastritis, colitis, dermatitis, and post-traumatic and repetitive strain injuries) result in enormous morbidity and societal cost, they remain poorly understood. Specifically, it is not known whether novel mechanisms different from those of acute inflammatory pain are involved, which is a critical point for the design of rational therapies.

Because chronic inflammatory pain states can follow an episode of acute inflammation (Lockwood, 1989; MacIntyre et al., 1995; Melhorn, 1998), we investigated whether acute inflammation can induce a long-lasting increase in the sensitivity to inflammatory hyperalgesic mediators. Such an increased sensitivity could underlie the development of a chronic pain syndrome and could be used to identify second messenger systems that contribute to chronic inflammatory states. In these experiments, we studied rats previously treated with the inflammatory agent carrageenan, at a dose that produces only short-lived inflammation and hyperalgesia (Guilbaud et al., 1989; Dawson et al., 1991). We found that this treatment resulted in a long-lasting increase in subsequent sensitivity to hyperalgesic inflammatory mediators. We also evaluated the initiation, duration, and mechanisms, including contributing second messengers, underlying this longlasting hypersensitivity to proinflammatory mediators.

Received Oct. 28, 1999; revised Feb. 18, 2000; accepted March 27, 2000.

This work was funded by National Institutes of Health Grant NS21647. We acknowledge many helpful discussions with Drs. David Reichling, Philip Heller, and Paul Green.

Correspondence should be addressed to Dr. K. O. Aley, National Institutes of Health Pain Center, University of California, San Francisco, Box 0440, San Francisco, CA 94143-0440. E-mail: aley@itsa.ucsf.edu.

Copyright () 2000 Society for Neuroscience $0270-6474 / 00 / 204680-06 \$ 15.00 / 0$ inhibitor of several PKC isozymes and a selective PKC $\epsilon$ inhibitor antagonized this prolonged hyperalgesic response equally. Acute carrageenan hyperalgesia could be inhibited by PKA or PKG antagonists. However, these antagonists did not inhibit development of the hypersensitivity to inflammatory mediators. Our findings indicate that different second messenger pathways underlie acute and prolonged inflammatory pain.

Key words: carrageenan; chronic pain; inflammation; prostaglandin E2; protein kinase $C \epsilon$; second messenger

\section{MATERIALS AND METHODS}

Animals. Experiments were performed on male Sprague Dawley rats (200-250 gm; Bantin-Kingman, Fremont, CA). Animals were housed in groups of two under a $12 \mathrm{hr}$ light/dark cycle (lights on at 7:00 A.M.). Food and water were available ad libitum. All behavioral testing was done between 10:00 A.M. and 4:00 P.M. Experiments were performed under approval of the Institutional Animal Care and Use Committee of the University of California, San Francisco.

Behavioral testing. The nociceptive flexion reflex (Randall-Selitto pawwithdrawal test) was quantified with a Basile Analgesymeter (Stoelting, Chicago, IL), which applies a linearly increasing mechanical force to the dorsum of the rat's hindpaw. Three readings were taken at $5 \mathrm{~min}$ intervals, and their mean was considered the baseline threshold. Groups that were compared with to determine effect of drug administration had similar baseline thresholds. Mechanical threshold was redetermined at various time points after drug administration. These time points were determined based on the latency and duration of action of each drug used in the study. The mean of three readings (taken at intervals of $5 \mathrm{~min}$, the last reading corresponding to the time specified [always taken at least at $30 \mathrm{~min}$ and $4 \mathrm{hr}$ for prostaglandin $\left.\mathrm{E}_{2}\left(\mathrm{PGE}_{2}\right)\right]$ after drug treatment) was used to calculate the percentage change from the baseline threshold. To determine the carrageenan dose to be used in the study, the effect of different doses $(0.1-2 \%)$ were evalvated studied. The time at which each drug had a maximal effect also was considered in timing the measurement of the paw-withdrawal threshold (maximum effect for carrageenan at $4 \mathrm{hr}$ and for the other drugs at $30 \mathrm{~min}$ ). To study the onset of carrageenan-induced changes in response to hyperalgesic inflammatory mediators, we injected rats with $\mathrm{PGE}_{2}$ at various times $(0.5-96 \mathrm{hr})$ after injection of carrageenan.

Drug administration. The drugs used in this study were as follows: $\mathrm{PGE}_{2}$ (direct-acting hyperalgesic inflammatory mediator), $\lambda$ carrageenan (inflammatory agent), $N^{\mathrm{G}}$-methyl-L-arginine (L-NMA) (nitric oxide synthase inhibitor), 2-[(2-bis - [carboxymethyl] amino-5-methylphenoxy) methyl]-6-methoxy-8-bis [carboxymethy] aminoquinoline (Quin-2) (calcium chelator), 3,4,5-trimethoxybenzoic acid 8-(diethylamino) octyl ester (TMB-8) (inhibitor of intracellular $\mathrm{Ca}^{2+}$ transport), and 5-hydroxytryptamine (5-HT, serotonin) (all from Sigma, St. Louis, MO); Walsh inhibitor peptide (WIPTIDE) [protein kinase A (PKA) inhibitor 5-22 amide; Peninsula Laboratories, Belmont CA]; and $\{1 \mathrm{H}-$ $[1,2,4]$ oxadiazolo[4,3-a]quinoxalin-1-one $\}$ (ODQ) (guanylyl cyclase inhibitor), an inhibitor of protein kinase $\mathrm{G}$ (PKG) (peptide with sequence, H-Arg-Lys-Arg-Ala-Arg-Lys-Glu-PH) that corresponds to a nonphos- 


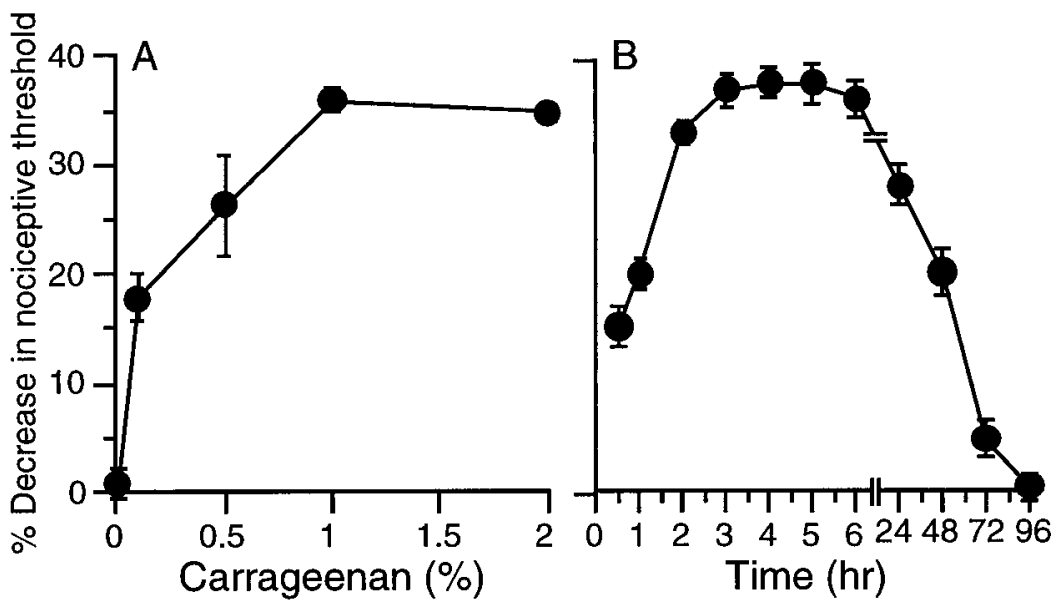

Figure 1. A, Dose (0.1-2\%)-response curve of carrageenan (Carr; $n=12$ ) induced mechanical hyperalgesia measured at $4 \mathrm{hr}$ in the hindpaw of the normal rat. The Randall-Selitto paw-withdrawal test is an established method to assess heightened nociception in animals in which this subjective experience of pain cannot be directly determined. Measures using this technique have been shown to correlate with pain-like behaviors in animals. $B$, Time course of hyperalgesia induced by carrageenan $1 \%$ ( 5 $\mu \mathrm{l}, n=24)$ in normal rats. phorylatable analog $\left(\mathrm{Ser}^{32}\right.$ to $\mathrm{Ala}^{32}$ ) of histone $\mathrm{H}_{2} \mathrm{~B}$ (residues 29-35), bisindolylmalemide $1 \mathrm{HCl}$ (Bis) [protein kinase $\mathrm{C}$ (PKC) inhibitor] (all from Calbiochem-Novabiochem, La Jolla, CA); (+)-5-methyl-10,11dihydro-5H-dibenzo [a,d] cyclohepten-5,10-imine maleate (MK-801) (NMDA receptor antagonist) and carboxyethyl phenethylamino- $5^{\prime}-N$ ethylcarboxamido adenosine $\mathrm{HCl}$ (CGS-21680) (an adenosine $\mathrm{A}_{2}$ agonist) (both from Research Biochemicals, Natick, MA). HDAPIGYD (pseudo $\epsilon$ RACK $(\psi \in \mathrm{R})$, a PKC $\epsilon$ agonist (Dorn et al., 1999) and $\mathrm{PKC} \epsilon \mathrm{V}_{1-2}$ peptide, H2N-EAVSLKPT-COOH, a PKC $\epsilon$ inhibitor (Gray et al., 1997) were synthesized by SynPep (Dublin, CA). The selection of the drug doses used in this study was based on dose-response curves determined during this as well as previous studies (Aley et al., 1995, 1998; Khasar et al., 1999a). The stock solution of $\operatorname{PGE}_{2}(1 \mu \mathrm{g} / 2.5 \mu \mathrm{l})$ was prepared in $10 \%$ ethanol, and additional dilutions were made in saline; the final concentration of ethanol was $\leq 1 \%$. All other drugs were dissolved in saline except ODQ, which was dissolved in DMSO and diluted with saline (final concentration of DMSO was $\leq 10 \%$ ). All drugs were administered intradermally in a volume of $5 \mu \mathrm{l} / \mathrm{paw}$. For test agents with low cell membrane permeability (i.e., WIPTIDE, PKC inhibitor, and $\psi \in \mathrm{R}), 2 \mu \mathrm{l}$ of distilled water was injected first, in the same syringe as the test agent, to produce hypo-osmotic shock and thus transiently permeabilize the cell membrane (Keeney and Linn, 1990; Lepers et al., 1990; Schulz, 1990). When drug combinations were used, they were administered at 5 min intervals with the drug mentioned first, the antagonist, administered first. All of the drugs except carrageenan were administered using a 30 gauge hypodermic needle. Because of its high viscosity, carrageenan was injected using a 27 gauge needle. All drugs were administered either to control rats or on days 5 or 21 after carrageenan. After injection of hyperalgesic inflammatory mediators, readings of nociceptive threshold were always taken at $30 \mathrm{~min}$ and $4 \mathrm{hr}$ and sometimes at other time points to determine the time course.

Statistical analysis. Data are presented as mean \pm SEM; means were compared by ANOVA. Differences between pairs of means were analyzed by Scheffe's post hoc test and were considered significant at $p<$ 0.05 .

\section{RESULTS}

\section{Carrageenan induces a long-term prolongation of inflammatory mediator-induced hyperalgesia}

We hypothesized that a low dose of an inflammatory agent such as carrageenan would produce a short-term (several days) hyperalgesia from which the animal would fully recover, but might also induce a long-lasting heightened hyperalgesic response to inflammatory mediators. By measuring the carrageenan dose-response relationship (Fig. $1 A$; see Materials and Methods), we determined that $5 \mu \mathrm{l}$ of $1 \%$ carrageenan (w/v in physiological saline) resulted in swelling, erythema, and reduced paw-withdrawal threshold to mechanical pressure beginning 30-60 min after injection, reaching a maximum between $2-4 \mathrm{hr}$, and resolving within $72 \mathrm{hr}$ (Fig. 1A,B).

Intradermal injection of the inflammatory mediators $\mathrm{PGE}_{2}, 5-\mathrm{HT}$, or the $\mathrm{A}_{2}$ adenosine receptor agonist CGS-21680, at the same site into which carrageenan had been injected $5 \mathrm{~d}$ earlier, resulted in a prolonged mechanical hyperalgesia lasting $>24 \mathrm{hr}$ (Fig. 2A). This ability of carrageenan to prolong hyperalgesia induced by inflammatory mediators persisted for at least 3 weeks after carrageenan administration (Fig. 2B). In comparison, in control rats exposed to vehicle without carrageenan, $\mathrm{PGE}_{2}$, CGS-21680, and 5-HT produced transient hyperalgesia lasting $<4 \mathrm{hr}$ (Fig. $2 C$ ).

\section{Novel mechanism of prolonged $\mathrm{PGE}_{\mathbf{2}}$-induced hyperalgesia}

We next examined the second messengers that mediate the ability of carrageenan to prolong hyperalgesia induced by inflammatory

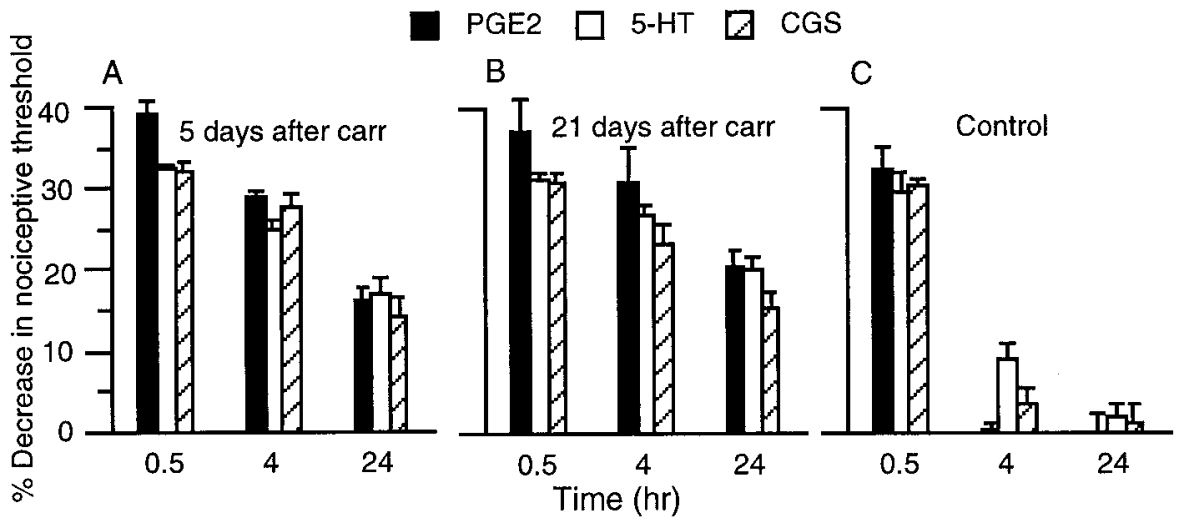

Figure 2. $A, \mathrm{PGE}_{2}(100 \mathrm{ng}, n=24), 5-\mathrm{HT}(1 \mu \mathrm{g}$, $n=6)$, and CGS-21680 (100 ng, $n=6$ )-induced mechanical hyperalgesia at $30 \mathrm{~min}, 4 \mathrm{hr}$, and $24 \mathrm{hr}$ after injection in rats treated $5 \mathrm{~d}$ previously with carrageenan. $B$, Mechanical hyperalgesia induced by $\mathrm{PGE}_{2}(n=12), 5$-HT $(n=6)$, and CGS-21680 $(n=6)$ at $30 \mathrm{~min}, 4 \mathrm{hr}$, and $24 \mathrm{hr}$ after injection in rats treated $21 \mathrm{~d}$ previously with carrageenan. $C$, Time course of PGE $_{2}^{-}$, 5-HT-, and CGS-21680induced mechanical hyperalgesia in rats $5 \mathrm{~d}$ after vehicle used for carrageenan $(n=12$ each). 


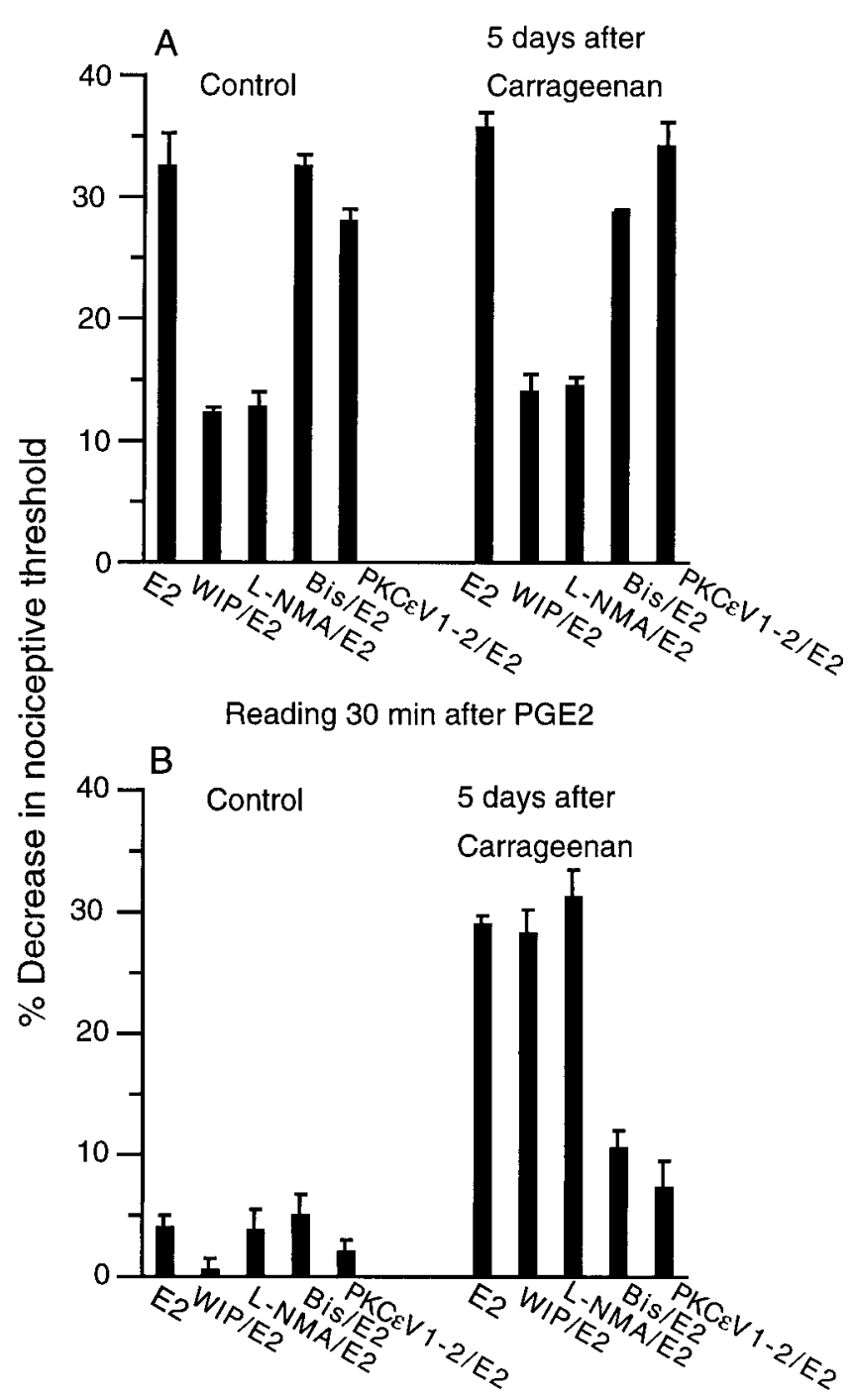

Reading $4 \mathrm{hr}$ after PGE2

Figure 3. $A$, Effect of PKA inhibitor WIPTIDE (WIP/E2; $1 \mu \mathrm{g} / 100 \mathrm{ng}$, $n=24)$, nitric oxide synthase inhibitor $N^{\mathrm{G}}$-methyl-L-arginine $(L-N M A$ / $E 2 ; 1 \mu \mathrm{g} / 100 \mathrm{ng}, n=12$ ), PKC inhibitor bisindolylmalemide 1 hydrochloride (Bis/E2; $1 \mu \mathrm{g} / 100 \mathrm{ng}, n=12)$, PKC $\epsilon$ inhibitor $(P K C \epsilon V 1-2 / E 2 ; 1$ $\mu \mathrm{g} / 100 \mathrm{ng}, n=12$ ), administered 5 min before $\mathrm{PGE}_{2}$, on $\mathrm{PGE}_{2}(E 2)$ induced mechanical hyperalgesia measured at 30 min after $\mathrm{PGE}_{2}$ injection in control rats and in rats treated $5 \mathrm{~d}$ previously with carrageenan. $B$, Effect of PKA inhibitor WIP/E2 $(n=24)$, nitric oxide synthase inhibitor $L-N M A / E 2(n=12)$, PKC inhibitor Bis/E2 $(n=12)$, PKC $\epsilon$ inhibitor $P K C \epsilon V 1-2 / E 2)(n=12)$, administered $5 \mathrm{~min}$ before $\mathrm{PGE}_{2}$, on $\mathrm{PGE}_{2}$ (E2)-induced mechanical hyperalgesia measured at $4 \mathrm{hr}$ after $\mathrm{PGE}_{2}$ injection in control rats and in rats treated $5 \mathrm{~d}$ previously with carrageenan.

mediators. To examine this issue, we evaluated $\mathrm{PGE}_{2}$-induced hyperalgesia and used inhibitors of second messenger pathways important in peripheral nociception. In control animals, previous treatment with the PKA inhibitor (WIPTIDE) or the nitric oxide synthase inhibitor (L-NMA) attenuated $\mathrm{PGE}_{2}$-induced mechanical hyperalgesia, whereas $\mathrm{Bis}$ ( $\mathrm{PKC}$ inhibitor) or $\mathrm{PKC} \epsilon \mathrm{V}_{1-2}$ (PKC $\epsilon$ inhibitor) was without effect (Fig. $3 A$ ). PKGI (PKG inhibitor), ODQ (guanylyl cyclase inhibitor), TMB-8 and Quin-2 (calcium antagonists), and MK-801 (NMDA receptor antagonist) were also without effect (data not shown). In rats treated with carrageenan 5 d previously, WIPTIDE or L-NMA inhibited the early phase of $\mathrm{PGE}_{2}$-stimulated hyperalgesia $30 \mathrm{~min}$ after injection of $\mathrm{PGE}_{2}$. This was similar to what was observed in control animals not pretreated with carrageenan (Fig. $3 A$ ). In contrast, neither WIPTIDE nor L-NMA inhibited the late phase (4 hr after injection) of $\mathrm{PGE}_{2}$-induced hyperalgesia observed in carrageenan pretreated rats (Fig. $3 B$ ). Bis and the PKC $\epsilon$ inhibitor did not reduce early $\mathrm{PGE}_{2}$-stimulated hyperalgesia in control or carrageenan pretreated rats (Fig. 3A). However, these agents inhibited the late phase of $\mathrm{PGE}_{2}$ hyperalgesia seen in carrageenan pretreated rats (Fig. $3 B$ ). The PKC $\epsilon$ inhibitor also inhibited the late phases of 5-HT and CGS-21680 hyperalgesia in carrageenan pretreated rats (data not shown). TMB-8 and Quin-2 or MK-801 had no effect on $\mathrm{PGE}_{2}$-induced hyperalgesia in carrageenan pretreated or control rats (data not shown).

We next investigated whether similar second messenger systems mediate acute carrageenan-induced hyperalgesia and the ability of carrageenan to prolong $\mathrm{PGE}_{2}$ hyperalgesia. Carrageenan-induced hyperalgesia was attenuated by an inhibitor of PKA or PKG (Fig. 4A). However, when $\mathrm{PGE}_{2}$ was administered after injection of WIPTIDE plus carrageenan or the PKG inhibitor plus carrageenan (Fig. 4B,C), a prolonged hyperalgesic response to $\mathrm{PGE}_{2}$ was still observed beginning $48 \mathrm{hr}$ after carrageenan injection (Fig. 4B,C).

\section{Administration of a PKC $\epsilon$ agonist is sufficient to induce the prolonged hyperalgesic response to $\mathrm{PGE}_{\mathbf{2}}$}

Because the long-term prolongation of $\mathrm{PGE}_{2}$ hyperalgesia was inhibited by PKC $\epsilon$ inhibitors, we evaluated whether specific activation of PKC $\epsilon$ could, like carrageenan, result in a similar longterm prolongation of $\mathrm{PGE}_{2}$ hyperalgesia. To perform these studies, we used the PKC $\epsilon$ peptide agonist $\psi \epsilon \mathrm{R}$ (Dorn et al., 1999).

Intradermal injection of the PKCe agonist $\psi \epsilon \mathrm{R}$ into the hindpaw of the rat produced a dose-dependent mechanical hyperalgesia (Fig. $5 A$ ), inhibitable by a nonselective $\mathrm{PKC}$ inhibitor (Bis) and a PKC $\epsilon$ selective inhibitor $\left(\mathrm{PKC} \mathrm{V}_{1-2}\right)$, but not by inhibitors of other second messenger pathways implicated in hyperalgesia (WIPTIDE, PKGI, ODQ, L-NMA, Quin-2, TMB-8, or MK801) (Fig. 5D). $\psi \in \mathrm{R}$-induced hyperalgesia lasted for $\sim 72 \mathrm{hr}$ (Fig. $5 C$ ). After recovery from $\psi \epsilon \mathrm{R}$-induced hyperalgesia, on the fifth day after administration of $\psi \epsilon \mathrm{R}$, the response to $\mathrm{PGE}_{2}$ was markedly prolonged (lasting $>24 \mathrm{hr}$ ) (Fig. $5 B$ ), similar to that observed after recovery from carrageenan hyperalgesia. As after carrageenan, Bis and PKC $\epsilon$ inhibitor, but not WIPTIDE, PKGI, ODQ, L-NMA, Quin-2, TMB-8, and MK801, attenuated the prolonged hyperalgesia induced by $\mathrm{PGE}_{2}$ (Fig. $5 E$ ). Instead, as found in carrageenan-pretreated rats, WIPTIDE inhibited only the early (30 min after injection) phase of $\mathrm{PGE}_{2}$ hyperalgesia in $\psi \in \mathrm{R}$-pretreated rats.

\section{DISCUSSION}

Although many mechanisms have been demonstrated to contribute to acute inflammatory pain, very little is known of the cellular changes underlying chronic inflammatory pain states. Recently, it has been suggested that sensitization and sprouting may be important mechanisms by which the CNS contributes to chronic inflammatory pain (Woolf and Doubell, 1994; Baranauskas and Nistri, 1998). We now demonstrate a novel peripheral pronociceptive mechanism initiated by acute inflammation, involving a PKC $\epsilon$-dependent prolongation of hyperalgesic responses to inflammatory mediators lasting several weeks after resolution of the initial acute inflammation. This prolonged response to inflammatory mediators constitutes a dramatic unprecedented plastic 


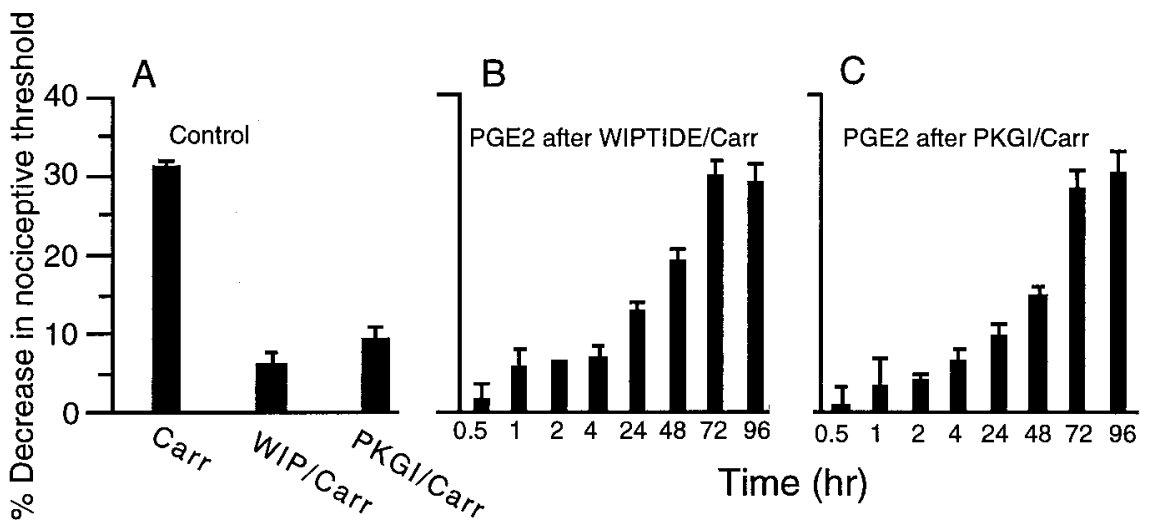

Figure 4. $A$, Effect of PKA inhibitor WIPTIDE $($ WIP/Carr; $n=24)$ and PKG inhibitor (PKGI/Carr; $n=8$ ) on carrageenan-induced mechanical hyperalgesia in the rat hindpaw. Agents were administered 5 min before carrageenan. All readings were taken 4 hr after carrageenan. $B, C$, Effect of $\mathrm{PGE}_{2}$ injected at different times (30 min to $96 \mathrm{hr}$ ) in different groups of rats after injection of carrageenan plus WIPTIDE $(B)$ or PKGI $(C)$. All readings were taken 4 hr after prostaglandin $\mathrm{E}_{2}$ injection. $n=6$ each group. change in primary afferent nociceptor function, most striking in the marked, sixfold or greater increase in duration of hyperalgesia after a single injection of $\mathrm{PGE}_{2}$ and in the persistence of this change for a 3 week period or more. In addition, this plastic change in the primary afferent nociceptor is not accompanied by a residual baseline hyperalgesia or by histopathological evidence of ongoing inflammation (Guilbaud et al., 1989; Dawson et al., 1991). Because in the dermis, the site of injection of all the test agents we used, PKC $\epsilon$ is present exclusively in nerve processes (Khasar et al., 1999a), this plastic change appears to occur in the primary afferent nociceptor.

Carrageenan, which we used to induce the initial inflammation, is a classic agent for the induction of experimental inflammation and inflammatory pain and is considered relevant to clinically important inflammatory pain states (Di Rosa, 1972; Dawson et al., 1991; Gilroy et al., 1999). In addition, the mediators for which we demonstrated the development of a prolonged response [PGE $2,5 \mathrm{HT}$, and purines (CGS-21680)] are known to be present at increased concentration at sites of inflammation (Foon et al., 1976; Driver et al., 1993; Villena et al., 1999) and are known to produce hyperalgesia by a direct action on primary afferent nociceptors (Taiwo and Levine, 1990, 1992; Gold et al., 1996). Therefore, the hyper-responsive state we describe, dependent on $\mathrm{PKC} \epsilon$, is very likely active in peripheral nociceptors in chronic
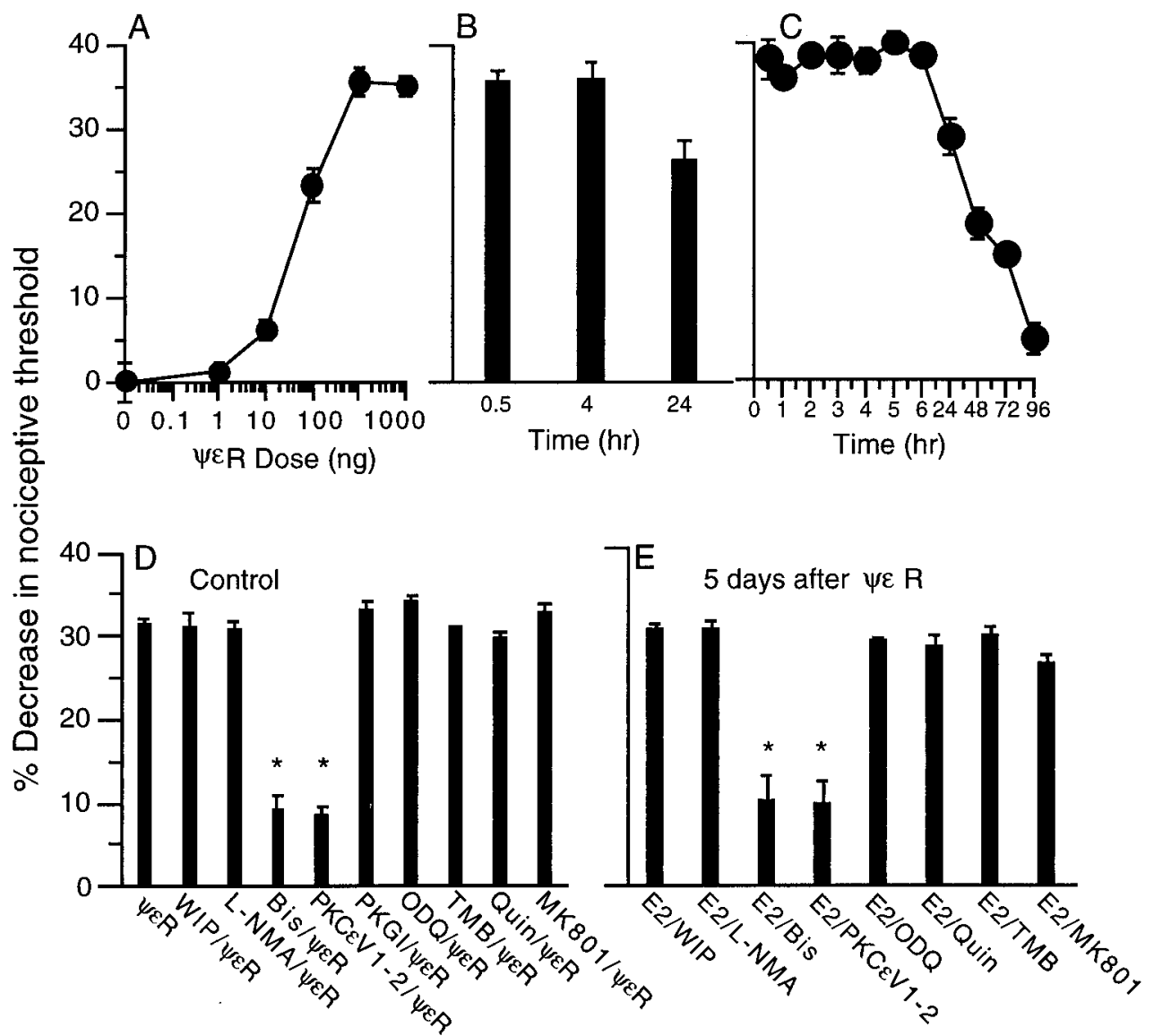

Figure 5. A, Dose-response curve of $\psi \in \mathrm{R}(0.1-10,000 \mathrm{ng}, n=8)$-induced mechanical hyperalgesia measured at 30 min in the hindpaw of the rat. $B, \mathrm{PGE}_{2}-$ induced hyperalgesia at $30 \mathrm{~min}, 4 \mathrm{hr}$, and $24 \mathrm{hr}$ in rats treated $5 \mathrm{~d}$ previously with $\psi \in \mathrm{R}(1 \mu \mathrm{g}, n=6) . C$, Time course of $\psi \in \mathrm{R}(1 \mu \mathrm{g} / \mathrm{paw}, n=12)$-induced hyperalgesia $(1 \mu \mathrm{g}) . D$, Role of second messengers important in $\psi \epsilon \mathrm{R}$-induced hyperalgesia. PKA inhibitor WIPTIDE (WIP/ $\Psi \epsilon R$; both $1 \mu \mathrm{g}, n=24$ ), the nitric oxide synthase inhibitor $N^{\mathrm{G}}$-methyl-Larginine $(L-N M A / \Psi \epsilon R$; both $1 \mu \mathrm{g}, n=$ $12)$, the PKC inhibitor bisindolylmalemide 1 hydrochloride (Bis/ $\Psi \epsilon R$; both $1 \mu \mathrm{g}, n=12$ ), the PKC $\epsilon$ inhibitor (PKC $\epsilon V 1-2 / \Psi \epsilon R$; both $1 \mu \mathrm{g}, n=12$ ), the PKG inhibitor $(P K G I / \Psi \epsilon R$; both $1 \mu \mathrm{g}$, $n=8$ ), the guanylyl cyclase inhibitor ODQ $(O D Q / \Psi \in R$; both $1 \mu \mathrm{g}, n=6)$, the calcium transport antagonist 3,4,5-trimethoxybezoic acid 8-(diethylamino) octyl ester $(T M B / \Psi \epsilon R$; both $1 \mu \mathrm{g}, n=6)$, the calcium chelator (2-[(2-bis-[carboxymethyl] amino-5-methylphenoxy) methyl]6-methoxy-8-bis[carboxymethy] aminoquinoline (Quin $/ \Psi \epsilon R$; both $1 \mu \mathrm{g}, n=$ 6 ), or the NMDA receptor antagonist MK-801 (MK801/ $\Psi \epsilon R$; both $1 \mu \mathrm{g}, n=8)$ 5 min before injection of $\psi \in \mathrm{R}(1 \mu \mathrm{g})$. All readings were taken $30 \mathrm{~min}$ after injection of $\psi \in \mathrm{R}$. E, Role of second messengers in $\mathrm{PGE}_{2}$-induced hyperalgesia in rats pretreated with $\psi \in \mathrm{R}$. Rats were administered the PKA inhibitor WIPTIDE $(E 2 / W I P ; 100 \mathrm{ng} / 1 \mu \mathrm{g}, n=6)$, the nitric oxide synthase inhibitor L-NMA $(E 2 / L-N M A ; 100 \mathrm{ng} / 1 \mu \mathrm{g}, n=6)$, the PKC inhibitor Bis $(E 2 / B i s ; 100 \mathrm{ng} / 1 \mu \mathrm{g}, n=10)$, the PKC $\epsilon$ inhibitor $(E 2 / P K C \epsilon V 1-2 ; 100 \mathrm{ng} / 1 \mu \mathrm{g}, n=6)$, the calcium antagonists Quin-2 and TMB-8 (E2/Quin and E2/TMB; both $100 \mathrm{ng} / 1 \mu \mathrm{g}$, both $n=6)$, or the NMDA receptor antagonist MK-801 (E2/MK801; $100 \mathrm{ng} / 1$ $\mu \mathrm{g}, n=10) 5 \mathrm{~min}$ before injection of $\mathrm{PGE}_{2}(E 2)(100 \mathrm{ng})$ on the fifth day after receiving $\psi \in \mathrm{R}(1 \mu \mathrm{g})$. All readings were taken $4 \mathrm{hr}$ after injection of PGE 
inflammatory pain. Such an exaggerated response to inflammatory mediators may explain the inordinate and lasting responses observed in patients with chronic inflammatory pain syndromes after minor stimuli (Lockwood, 1989; MacIntyre et al., 1995; Melhorn, 1998).

In our model, mild acute carrageenan hyperalgesia could be blocked without inhibiting subsequent enhanced responsiveness to $\mathrm{PGE}_{2}$. This demonstrated that enhanced responsiveness to $\mathrm{PGE}_{2}$ was not dependent on the preceding acute hyperalgesia. This finding allowed us to determine that enhanced responsiveness to $\mathrm{PGE}_{2}$ was present as early as $48 \mathrm{hr}$ after injection of carrageenan. These observations suggest that development of a propensity for persistent chronic inflammatory pain may occur after a period of only minimal hyperalgesia, providing an explanation for instances in which chronic inflammatory pain develops without an episode of preceding overt acute inflammation.

Pronociceptive plastic changes in CNS circuitry are well established (Woolf and Doubell, 1994; Mannion et al., 1996; Baranauskas and Nistri, 1998). The search for such changes in the periphery, however, has received little attention, although there are recent reports of altered gene expression in primary afferent neurons stimulated by NGF and electrical activity (Gilchrist et al., 1991; McCarson and Krause, 1994; Nahin and Byers, 1994; Black et al., 1997; Itoh et al., 1997; Tonra and Mendell, 1998; Fjell et al., 1999; Woolf and Costigan, 1999). The time of onset of $\sim 48$ hr for the development of long-term prolongation of hyperalgesic responses to inflammatory mediators is compatible with gene expression followed by transport or newly synthesized protein to peripheral terminals.

Although our data do not exclude actions by other isozymes of $\mathrm{PKC}$, that the epsilon isozyme alone, of PKC, is responsible is supported by the observations that the prolonged response to inflammatory mediators was totally prevented by injection of a specific PKC $\epsilon$ inhibitor and that the injection of a PKC $\epsilon$ agonist alone resulted in a similar prolonged hyperalgesic response. PKC $\epsilon$ is known also to contribute to acute nociception, specifically to acute hyperalgesia produced by epinephrine (Khasar et al., 1999a,b), which may be present at increased levels during inflammation (Cunha et al., 1991; Mikhailov and Rusanova, 1993). That there is a different function of PKC $\epsilon$ in prolonged hyperalgesia compared with acute nociception is suggested by the chronic ( $>24 \mathrm{hr}$ ) nature of the resultant hyperalgesia and the apparent novel coupling of PKC $\epsilon$ to the $\mathrm{PGE}_{2}$ receptor, a phenomenon not seen in acute hyperalgesia produced by $\mathrm{PGE}_{2}$ (Levine and Reichling, 1999).

In summary, we have established, for the first time, a plastic pronociceptive mechanism, most likely in nociceptors, that is dependent on PKC $\epsilon$ and may have a role in chronic inflammatory pain states. The dependence on a mechanism not found with acute hyperalgesia and its presence after even mild inflammation has important clinical implications. Our experimental paradigm provides a model for the investigation of other cellular mechanisms that may contribute to chronic inflammatory pain. It should be possible, using this model, to obtain valuable information for the rational development of targeted therapies for both active disease and remission of chronic inflammatory pain states, such as arthritis, bronchitis, asthma, dermatitis, inflammatory bowel disease, and repetitive strain injuries, which contribute greatly to morbidity worldwide. Finally, because the targeted pronociceptive mechanism is peripheral, at the site of pain, it may be possible to administer analgesic therapies locally with minimal or no systemic side effects.

\section{REFERENCES}

Aley KO, Khasar SG, Levine JD (1995) Multiple second messenger systems act sequentially to mediate rolipram-induced prolongation of prostaglandin E2-induced mechanical hyperalgesia in the rat. Neuroscience 64:769-776.

Aley KO, McCarter G, Levine JD (1998) Nitric oxide signaling in pain and nociceptor sensitization in the rat. J Neurosci 18:7008-7014.

Baranauskas G, Nistri A (1998) Sensitization of pain pathways in the spinal cord: cellular mechanisms. Prog Neurobiol 54:349-365.

Black JA, Langworthy K, Hinson AW, Dib-Hajj SD, Waxman SG (1997) NGF has opposing effects on $\mathrm{Na}^{+}$channel III and SNS gene expression in spinal sensory neurons. NeuroReport 8:2331-2335.

Cesare P, McNaughton P (1997) Peripheral pain mechanisms. Curr Opin Neurobiol 7:493-499.

Cunha FQ, Lorenzetti BB, Poole S, Ferreira SH (1991) Interleukin-8 as a mediator of sympathetic pain. Br J Pharmacol 104:765-767.

Dawson J, Sedgwick AD, Edwards JC, Lees P (1991) A comparative study of the cellular, exudative and histological responses to carrageenan, dextran and zymosan in the mouse. Int $\mathbf{J}$ Tissue React 13:171-185.

Di Rosa M (1972) Biological properties of carrageenan. J Pharm Pharmacol 24:89-102.

Dorn GWI, Sourougon MC, Liron T, Chen C-H, Gray MO, Zhou HZ, Csukai M, Wu G, Lorenz JN, Mochly-Rosen D (1999) Sustained in vivo cardiac protection by a rationally designed peptide that causes $\epsilon$ protein kinase $\mathrm{C}$ translocation. Proc Natl Acad Sci USA 96:12798-12803.

Driver AG, Kukoly CA, Ali S, Mustafa SJ (1993) Adenosine in bronchoalveolar lavage fluid in asthma. Am Rev Respir Dis 148:91-97.

Fjell J, Cummins TR, Davis BM, Albers KM, Fried K, Waxman SG, Black JA (1999) Sodium channel expression in NGF-overexpressing transgenic mice. J Neurosci Res 57:39-47.

Foon KA, Wahl SM, Oppenheim JJ, Rosenstreich DL (1976) Serotonininduced production of a monocyte chemotactic factor by human peripheral blood leukocytes. J Immunol 117:1545-1552.

Gilchrist CA, Morrison CF, Chapman KE, Harmar AJ (1991) Identification of nerve growth factor-responsive sequences within the $5^{\prime}$ region of the bovine preprotachykinin gene. DNA Cell Biol 10:743-749.

Gilroy DW, Colville-Nash PR, Willis D, Chivers J, Paul-Clark MJ, Willoughby DA (1999) Inducible cyclooxygenase may have antiinflammatory properties. Nat Med 5:698-701.

Gold MS, Reichling DB, Shuster MJ, Levine JD (1996) Hyperalgesic agents increase a tetrodotoxin-resistant $\mathrm{Na}^{+}$current in nociceptors. Proc Natl Acad Sci USA 93:1108-1112.

Gray MO, Karliner JS, Mochly-Rosen D (1997) A selective epsilonprotein kinase $\mathrm{C}$ antagonist inhibits protection of cardiac myocytes from hypoxia-induced cell death. J Biol Chem 272:30945-30951.

Guilbaud G, Benoist JM, Eschalier A, Kayser V, Gautron M, Attal N (1989) Evidence for central phenomena participating in the changes of responses of ventrobasal thalamic neurons in arthritic rats. Brain Res 484:383-388.

Itoh K, Ozaki M, Stevens B, Fields RD (1997) Activity-dependent regulation of N-cadherin in DRG neurons: differential regulation of $\mathrm{N}$-cadherin, NCAM, and L1 by distinct patterns of action potentials. J Neurobiol 33:735-748.

Keeney S, Linn S (1990) A critical review of permeabilized cell systems for studying mammalian DNA repair. Mutat Res 236:239-252.

Khasar SG, Lin Y-H, Martin A, Dadgar J, McMahon T, Wang D, Hundle B, Aley KO, Isenberg W, McCarter G, Green PG, Hodge CW, Levine JD, Messing RO (1999a) A novel nociceptor signaling pathway revealed in protein kinase C mutant mice. Neuron 24:253-260.

Khasar SG, McCarter G, Levine JD (1999b) Epinephrine produces a beta-adrenergic receptor-mediated mechanical hyperalgesia and in vitro sensitization of rat nociceptors. J Neurophysiol 81:1104-1112.

Lepers A, Cacan R, Verbert A (1990) Permeabilized cells as a way of gaining access to intracellular organelles: an approach to glycosylation reactions. Biochimie 72:1-5.

Levine JD, Reichling DB (1999) Peripheral mechanisms of inflammatory pain. In: Textbook of pain (Wall PD, Melzack R, Bonica JJ, eds), pp 59-84. New York: Churchill Livingston.

Lockwood AH (1989) Medical problems of musicians. N Engl J Med 320:221-227.

MacIntyre DL, Reid WD, McKenzie DC (1995) Delayed muscle soreness. The inflammatory response to muscle injury and its clinical implications. Sports Med 20:24-40. 
Mannion RJ, Doubell TP, Coggeshall RE, Woolf CJ (1996) Collateral sprouting of uninjured primary afferent A-fibers into the superficial dorsal horn of the adult rat spinal cord after topical capsaicin treatment to the sciatic nerve. J Neurosci 16:5189-5195.

McCarson KE, Krause JE (1994) NK-1 and NK-3 type tachykinin receptor mRNA expression in the rat spinal cord dorsal horn is increased during adjuvant or formalin-induced nociception. J Neurosci 14:712-720.

Melhorn J (1998) Cumulative trauma disorders and repetitive strain injuries. The future. Clin Orthop 351:107-126.

Mikhailov VV, Rusanova AG (1993) The interrelationship of the catecholamine and protein content of the tissue of the submandibular salivary glands and the mucosa during the secretory cycle in chronic inflammation of the oral soft tissues. Biull Eksp Biol Med 116:472-474.

Nahin RL, Byers MR (1994) Adjuvant-induced inflammation of rat paw is associated with altered calcitonin gene-related peptide immunoreactivity within cell bodies and peripheral endings of primary afferent neurons. J Comp Neurol 349:475-485.
Schulz I (1990) Permeabilizing cells: some methods and applications for the study of intracellular processes. Methods Enzymol 192:280-300.

Taiwo YO, Levine JD (1990) Direct cutaneous hyperalgesia induced by adenosine. Neuroscience 38:757-762.

Taiwo YO, Levine JD (1992) Serotonin is a directly-acting hyperalgesic agent in the rat. Neuroscience 48:485-490.

Tonra JR, Mendell LM (1998) Effects of postnatal anti-NGF on the development of CGRP-IR neurons in the dorsal root ganglion. J Comp Neurol 392:489-498.

Villena C, Vivas JM, Villar AM (1999) Ocular inflammation models by topical application: croton-oil induced uveitis. Curr Eye Res 18:3-9.

Woolf CJ, Costigan M (1999) Transcriptional and posttranslational plasticity and the generation of inflammatory pain. Proc Natl Acad Sci USA 96:7723-7730.

Woolf CJ, Doubell TP (1994) The pathophysiology of chronic painincreased sensitivity to low threshold A beta-fibre inputs. Curr Opin Neurobiol 4:525-534. 